Supporting Information

\title{
Additive fabrication of conductive patterns by a template transfer process based on benzotriazole adsorption as a separation layer
}

Yu Chang, and Zhen-Guo Yang*

Department of Materials Sciences, Fudan Unversity, 220 Handan Road, Shanghai,

China

Corresponding Author

* Tel: +86-21-65642523, Fax: +86-21-65103056, E-mail: zgyang@fudan.edu.cn

(Z.-G. Yang) 
Table S1. Fitting results of EIS spectra recorded for the carrier copper foil at different immersion times.

\begin{tabular}{|c|c|c|c|c|c|c|c|c|c|}
\hline Time & $\begin{array}{l}\mathrm{Re} \\
\Omega \cdot \mathrm{cm}^{2}\end{array}$ & $\begin{array}{l}\text { Q1 } \\
\Omega^{-1} \cdot \mathrm{S}^{\mathrm{n}} \cdot \mathrm{cm}^{-2}\end{array}$ & $\mathrm{n} 1$ & $\begin{array}{l}\mathrm{R} 1 \\
\Omega \cdot \mathrm{cm}^{2}\end{array}$ & $\begin{array}{l}\mathrm{Q} 2 \\
\Omega^{-1} \cdot \mathrm{S}^{\mathrm{n}} \cdot \mathrm{cm}^{-2}\end{array}$ & $\mathrm{n} 2$ & $\begin{array}{l}\mathrm{R} 2 \\
\Omega \cdot \mathrm{cm}^{2}\end{array}$ & $\begin{array}{l}\mathrm{C} \\
\mathrm{F}\end{array}$ & $\begin{array}{l}\mathrm{d} \\
\mathrm{nm}\end{array}$ \\
\hline 1 & 1.920 & $1.435 \cdot 10^{-4}$ & 0.6219 & 0.4900 & $1.263 \cdot 10^{-5}$ & 0.976 & 611.5 & $1.120 \cdot 10^{-5}$ & 0.4186 \\
\hline 5 & 3.832 & $1.044 \cdot 10^{-4}$ & 0.6910 & 0.3463 & $8.007 \cdot 10^{-6}$ & 1 & 738.5 & $8.007 \cdot 10^{-6}$ & 0.5858 \\
\hline 10 & 1.975 & $8.434 \cdot 10^{-5}$ & 0.7205 & 0.7952 & $6.670 \cdot 10^{-6}$ & 1 & 945.7 & $6.670 \cdot 10^{-6}$ & 0.7032 \\
\hline 30 & 1.940 & $7.920 \cdot 10^{-5}$ & 0.7273 & 1.222 & $6.464 \cdot 10^{-6}$ & 1 & 1033 & $6.464 \cdot 10^{-6}$ & 0.7256 \\
\hline 60 & 1.563 & $7.819 \cdot 10^{-5}$ & 0.6794 & 0.9257 & $6.419 \cdot 10^{-6}$ & 1 & 1119 & $6.419 \cdot 10^{-6}$ & 0.7307 \\
\hline 120 & 3.547 & $7.626 \cdot 10^{-5}$ & 0.7331 & 1.122 & $6.269 \cdot 10^{-6}$ & 1 & 1105 & $6.269 \cdot 10^{-6}$ & 0.7482 \\
\hline 300 & 1.933 & $6.801 \cdot 10^{-5}$ & 0.7313 & 0.8179 & $5.967 \cdot 10^{-6}$ & 1 & 1256 & $5.967 \cdot 10^{-6}$ & 0.7861 \\
\hline 600 & 0.9851 & $7.321 \cdot 10^{-5}$ & 0.7232 & 2.315 & $5.812 \cdot 10^{-6}$ & 1 & 1274 & $5.812 \cdot 10^{-6}$ & 0.8071 \\
\hline 1200 & 1.182 & $6.789 \cdot 10^{-5}$ & 0.7302 & 1.858 & $5.848 \cdot 10^{-6}$ & 1 & 1299 & $5.848 \cdot 10^{-6}$ & 0.8021 \\
\hline
\end{tabular}


Table S2. Fitting results of EIS spectra recorded for the carrier copper foil and peeled copper film with different peeling times.

\begin{tabular}{|c|c|c|c|c|c|c|c|c|c|}
\hline $\begin{array}{l}\text { Peeling } \\
\text { times }\end{array}$ & $\begin{array}{l}\mathrm{Re} \\
\Omega \cdot \mathrm{cm}^{2}\end{array}$ & $\begin{array}{l}\mathrm{Q} 1 \\
\Omega^{-1} \cdot \mathrm{S}^{\mathrm{n}} \cdot \mathrm{cm}^{-2}\end{array}$ & $\mathrm{n} 1$ & $\begin{array}{l}\mathrm{R} 1 \\
\Omega \cdot \mathrm{cm}^{2}\end{array}$ & $\begin{array}{l}\mathrm{Q} 2 \\
\Omega^{-1} \cdot \mathrm{S}^{\mathrm{n}} \cdot \mathrm{cm}^{-2}\end{array}$ & n2 & $\begin{array}{l}\mathrm{R} 2 \\
\Omega \cdot \mathrm{cm}^{2}\end{array}$ & $\begin{array}{l}\mathrm{C} \\
\mathrm{F}\end{array}$ & $\begin{array}{l}\mathrm{d} \\
\mathrm{nm}\end{array}$ \\
\hline 0 on $\mathrm{CC}^{\mathrm{a}}$ & 1.933 & $6.801 \cdot 10^{-5}$ & 0.7313 & 0.8179 & $5.967 \cdot 10^{-6}$ & 1 & 1256 & $5.967 \cdot 10^{-6}$ & 0.7861 \\
\hline 1 on $\mathrm{CC}$ & 1.665 & $8.883 \cdot 10^{-5}$ & 0.6356 & 0.3648 & $1.715 \cdot 10^{-5}$ & 0.9254 & 666.2 & $1.196 \cdot 10^{-5}$ & 0.3923 \\
\hline 1 on $\mathrm{PC}^{\mathrm{b}}$ & 1.729 & $1.122 \cdot 10^{-4}$ & 0.6753 & 0.4955 & $1.343 \cdot 10^{-5}$ & 0.9487 & 804.5 & $1.051 \cdot 10^{-5}$ & 0.4462 \\
\hline 2 on $\mathrm{CC}$ & 1.086 & $8.224 \cdot 10^{-5}$ & 0.5611 & 0.3588 & $4.256 \cdot 10^{-5}$ & 0.8693 & 607.3 & $2.457 \cdot 10^{-6}$ & 0.1909 \\
\hline 2 on $\mathrm{PC}$ & 2.136 & $3.354 \cdot 10^{-4}$ & 0.3509 & $2.654 \cdot 10^{-5}$ & $7.063 \cdot 10^{-5}$ & 0.8945 & 558.5 & $4.824 \cdot 10^{-5}$ & 0.0972 \\
\hline 3 on $\mathrm{CC}$ & 1.020 & $1.117 \cdot 10^{-4}$ & 0.4748 & 0.3839 & $5.031 \cdot 10^{-5}$ & 0.8605 & 547.8 & $2.810 \cdot 10^{-5}$ & 0.1669 \\
\hline 3 on $\mathrm{PC}$ & 2.391 & $6.996 \cdot 10^{-4}$ & 0.2301 & $9.671 \cdot 10^{-8}$ & $9.299 \cdot 10^{-5}$ & 0.8762 & 667 & $6.278 \cdot 10^{-5}$ & 0.0747 \\
\hline 4 on $\mathrm{CC}^{\mathrm{c}}$ & 2.293 & $5.767 \cdot 10^{-5}$ & 0.7180 & 0.5187 & $6.651 \cdot 10^{-6}$ & 0.9710 & 1087 & $5.812 \cdot 10^{-5}$ & 0.8171 \\
\hline
\end{tabular}

${ }^{a} \mathrm{CC}$ means carrier copper. The carrier copper foil immersed for $5 \mathrm{~min}$ is used.

${ }^{\mathrm{b}}$ PC means peeled copper film.

${ }^{\mathrm{c}}$ Before fourth peeling, the carrier copper foil is reimmersed for $5 \mathrm{~min}$. 


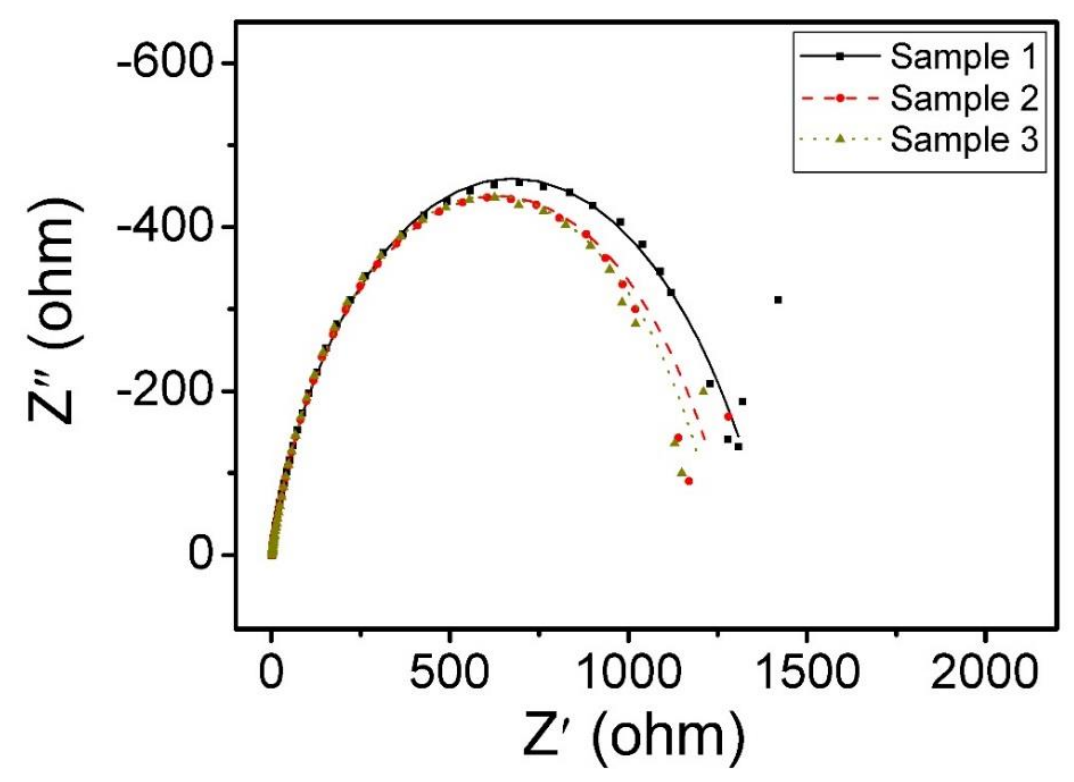

Figure S1. EIS curves of the carrier copper foil under the same BTA adsorption conditions. The adsorption parameters for sample 1-3 are $1 \mathrm{~cm}^{2}$ copper foil immersing in $0.5 \mathrm{wt} \%$ BTA water solution at $50{ }^{\circ} \mathrm{C}$ for $5 \mathrm{~min}$.

Table S3. Fitting results of EIS spectra recorded for the carrier copper foil under the same conditions ${ }^{\mathrm{a}}$.

\begin{tabular}{|c|c|c|c|c|c|c|c|c|c|}
\hline \multirow{2}{*}{ Sample } & $\mathrm{Re}$ & Q1 & \multirow{2}{*}{$\mathrm{n} 1$} & $\mathrm{R} 1$ & $\mathrm{Q} 2$ & \multirow{2}{*}{$\mathrm{n} 2$} & $\mathrm{R} 2$ & $\mathrm{C}$ & $\mathrm{d}$ \\
\hline & $\Omega \cdot \mathrm{cm}^{2}$ & $\Omega^{-1} \cdot \mathrm{S}^{\mathrm{n}} \cdot \mathrm{cm}^{-2}$ & & $\Omega \cdot \mathrm{cm}^{2}$ & $\Omega^{-1} \cdot \mathrm{S}^{\mathrm{n}} \cdot \mathrm{cm}^{-2}$ & & $\Omega \cdot \mathrm{cm}^{2}$ & $\mathrm{~F}$ & $\mathrm{~nm}$ \\
\hline 1 & 1.280 & $6.950 \cdot 10^{-5}$ & 0.6800 & 1.439 & $5.821 \cdot 10^{-6}$ & 1 & 1397 & $5.821 \cdot 10^{-6}$ & 0.8058 \\
\hline 2 & 1.298 & $7.637 \cdot 10^{-5}$ & 0.7062 & 1.296 & $6.672 \cdot 10^{-6}$ & 1 & 1295 & $6.672 \cdot 10^{-6}$ & 0.7030 \\
\hline 3 & 1.933 & $6.801 \cdot 10^{-5}$ & 0.7313 & 0.8179 & $5.967 \cdot 10^{-6}$ & 1 & 1256 & $5.967 \cdot 10^{-6}$ & 0.7861 \\
\hline
\end{tabular}

${ }^{\text {a }}$ Sample 1-3: $1 \mathrm{~cm}^{2}$ copper foil were immersed into $0.5 \mathrm{wt} \%$ BTA water solution at $50{ }^{\circ} \mathrm{C}$ for $5 \mathrm{~min}$.

The average thickness of the $\mathrm{Cu}-\mathrm{BTA}$ layer after 5 min BTA immersion is calculated to be $0.7650 \mathrm{~nm}$, and the standard deviation is calculated to be $0.05456 \mathrm{~nm}$. 


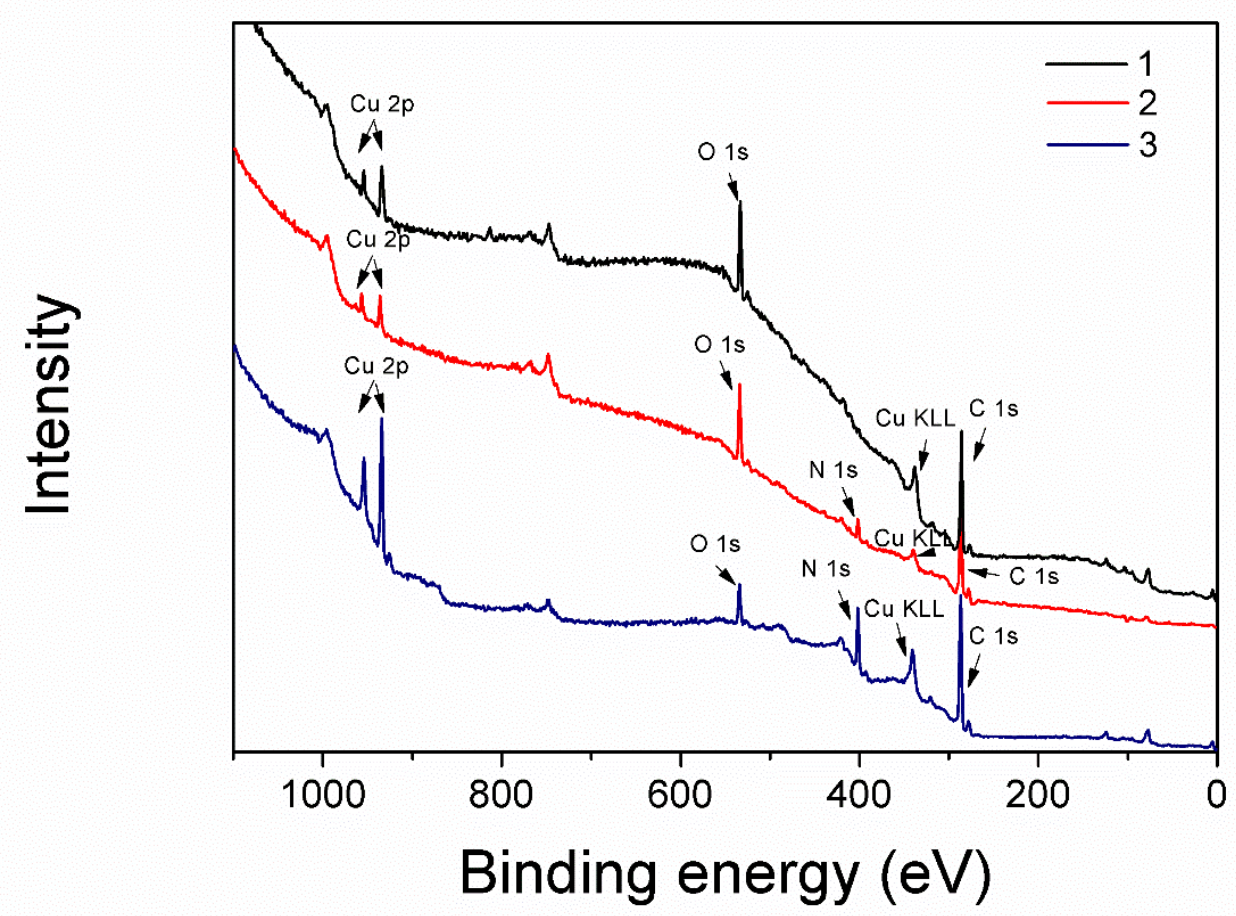

Figure S2. XPS spectra of the copper surface. 1 is the carrier copper surface before BTA immersion, 2 is the plated copper surface after peeling, 3 is the carrier copper after BTA immersion at $50^{\circ} \mathrm{C}$ for $5 \mathrm{~min}$. The main differences of three spectra are the $\mathrm{N}$ 1s peaks derived from BTA. The $\mathrm{N}$ 1s peak verifies the adsorption of the BTA to the carrier copper after BTA immersion comparing 1 and 3. It also verifies the separation of the BTA film during peeling comparing 2 and 3. C 1s peaks in all of the spectra are used for calibration, they cannot confirm the existence of $\mathrm{C}$ in the samples. 
Table S4. Peeling strengths of the plated film from the carrier foil at different BTA immersion times.

\begin{tabular}{ccc}
\hline Time & $\begin{array}{c}\text { Peeling strength } \\
\mathrm{N} / \mathrm{cm}\end{array}$ & $\begin{array}{c}\text { Standard Deviation } \\
\mathrm{s}\end{array}$ \\
\hline 1 & 2.95 & 0.835 \\
5 & 0.84 & 0.136 \\
10 & 0.22 & 0.0556 \\
30 & 0.21 & 0.0255 \\
60 & 0.12 & 0.0152 \\
120 & 0.069 & 0.0169 \\
300 & 0.074 & 0.0147 \\
600 & 0.070 & 0.00870 \\
1200 & 0.069 & 0.00849 \\
\hline
\end{tabular}

Table S5. Peeling strengths of the plated film from the carrier foil with different peeling times.

\begin{tabular}{ccc}
\hline Peeling times & $\begin{array}{c}\text { Peeling strength } \\
\mathrm{N} / \mathrm{cm}\end{array}$ & $\begin{array}{c}\text { Standard Deviation } \\
\mathrm{N} / \mathrm{cm}\end{array}$ \\
\hline 1 & 0.074 & 0.0147 \\
2 & 0.15 & 0.0208 \\
3 & 1.08 & 0.137 \\
Reimmersed in BTA \\
solution for 5 min
\end{tabular}




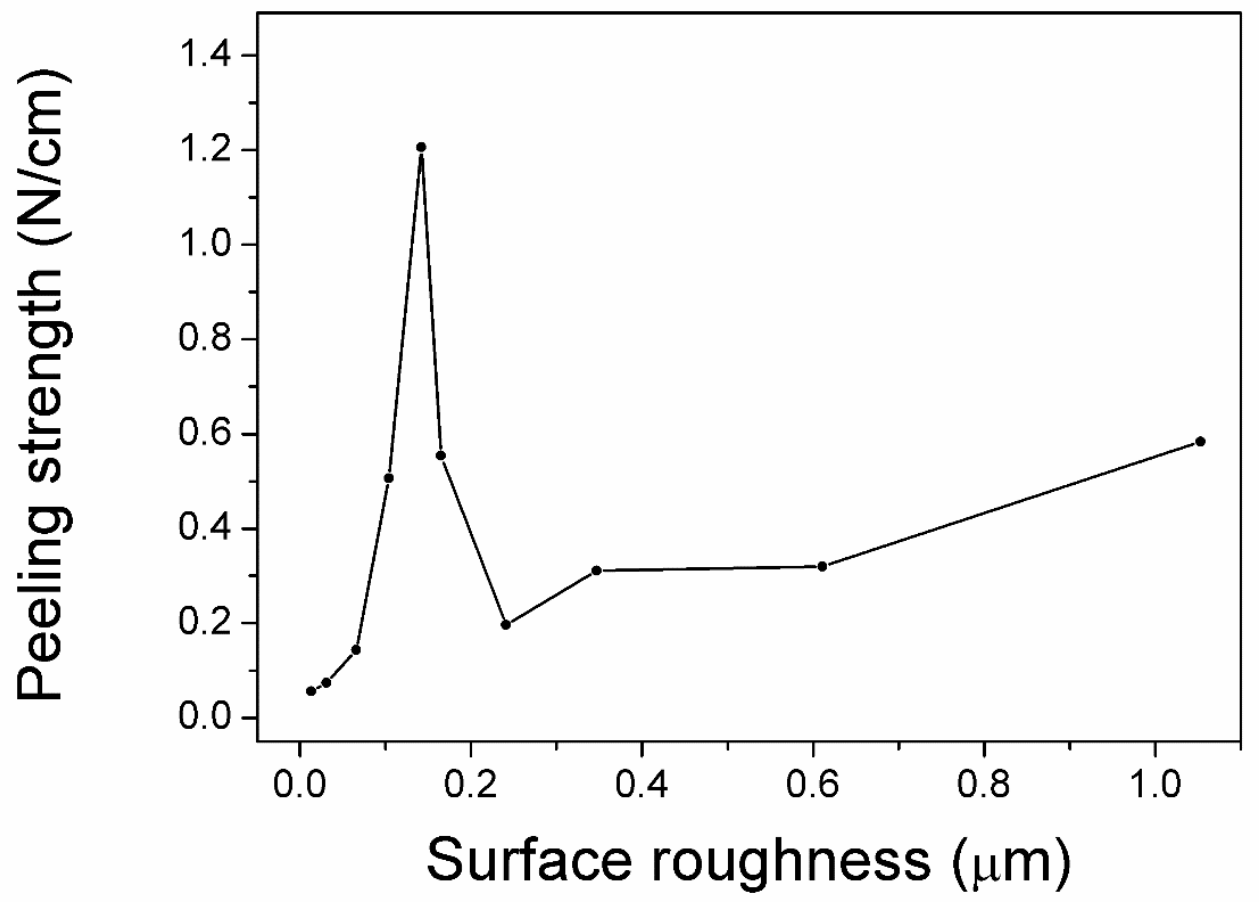

Figure S3. Relationship between the peeling strength of the plated copper film with the surface roughness of the carrier copper foil. The carrier copper foil was sanded to achieve different surface roughness. The sanded carrier copper foil was then immersed into $0.5 \mathrm{wt} \%$ BTA solution at $50^{\circ} \mathrm{C}$ for $5 \mathrm{~min}$, and electroplated for $5 \mathrm{~min}$ to grow copper film on the surface. The original surface roughness of the carrier copper foil is $0.031 \mu \mathrm{m}$, correspondingly, the peeling strength of the plated copper foil is measured to be $0.074 \mathrm{~N} / \mathrm{cm}$. After polishing, the carrier foil becomes smoother with a surface roughness of $0.013 \mu \mathrm{m}$, and the peeling strength decreases to $0.056 \mathrm{~N} / \mathrm{cm}$. The highest peeling strength approximately $1.2 \mathrm{~N} / \mathrm{cm}$ is achieved when the surface roughness of the carrier copper reach $0.14 \mu \mathrm{m}$. The peeling strength then decreases significantly when the surface roughness changes from $0.14 \mu \mathrm{m}$ to $0.24 \mu \mathrm{m}$. Afterward, with the increase of the surface roughness to $1.05 \mu \mathrm{m}$, the peeling strength grows slowly from $0.2 \mathrm{~N} / \mathrm{cm}$ to $0.6 \mathrm{~N} / \mathrm{cm}$. 
Table S6. Properties of the RFID tag circuitry fabricated by the template transfer process.

\begin{tabular}{lllll}
\hline & $\begin{array}{l}\text { Circuitry } \\
\text { material }\end{array}$ & $\begin{array}{l}\text { Circuitry } \\
\text { thickness }\end{array}$ & $\begin{array}{l}\text { Sheet } \\
\text { resistance }\end{array}$ & Resistivety \\
\hline Sample & Copper & $20.7 \mu \mathrm{m}$ & $0.97 \mathrm{~m} \Omega$ & $2.01 \mu \Omega \mathrm{cm}$ \\
Comparion* & Aluminum & $12.0 \mu \mathrm{m}$ & $2.36 \mathrm{~m} \Omega$ & $2.83 \mu \Omega \mathrm{cm}$ \\
\hline
\end{tabular}

*The comparion are the commercial RFID tag circuitry with the same pattern

(a)

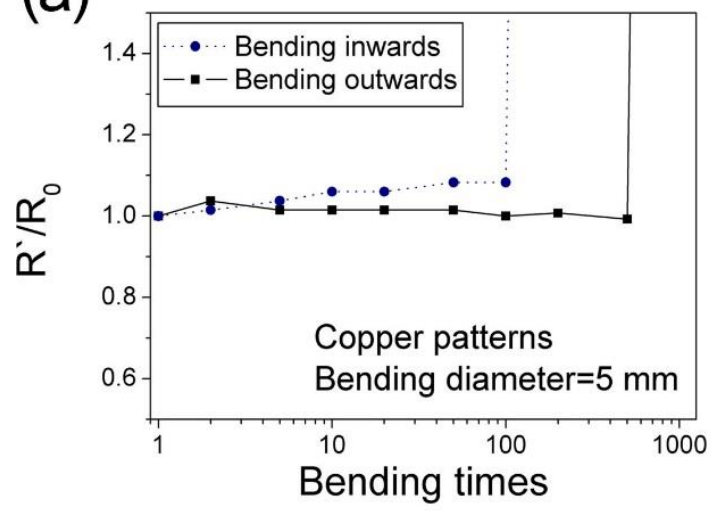

(c)

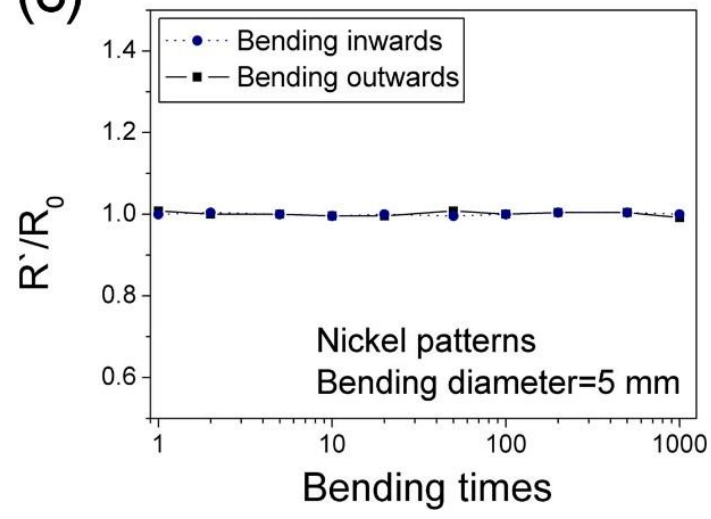

(b)

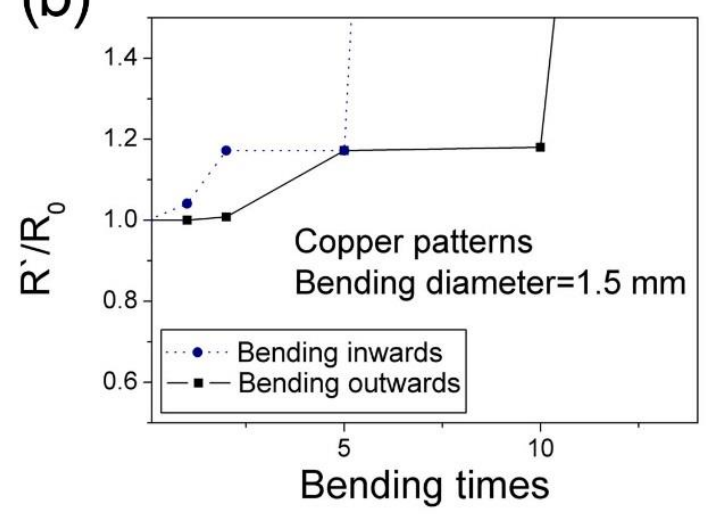

(d)

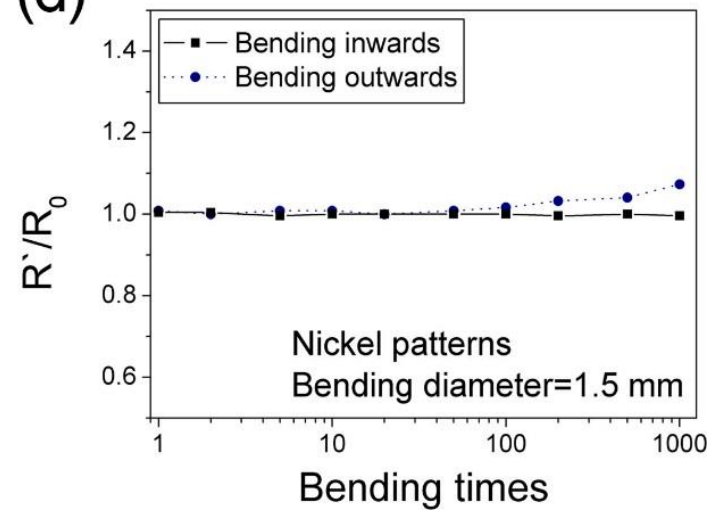

Figure S4. Resistance stability of the conducitive patterns after cyclical bending. The metal patterns about $20 \mu \mathrm{m}$ in thickness are adhered to the PET substrate about $90 \mu \mathrm{m}$ in thickness with the pressure-sensitive adhesive about $50 \mu \mathrm{m}$ in thickness. $\mathrm{R}$ ' is the resistance after bending, $\mathrm{R}_{0}$ is the original resistance, bending inwards means bending towards the metal patterns, bending outwards means bending towards the PET 
substrate. (a) and (b) are the resistance change of the copper patterns after cyclical bending with the bending diameters of $5 \mathrm{~mm}$ and $1.5 \mathrm{~mm}$. The copper patterns are electroplated and transferred following the experimental section. (c) and (d) are the resistance change of the nickel patterns after cyclical bending with the bending diameters of $5 \mathrm{~mm}$ and $1.5 \mathrm{~mm}$. The nickel electroplating bath contains nickel aminosulfonate $(380 \mathrm{~g} / \mathrm{L})$, nickel chloride $(30 \mathrm{~g} / \mathrm{L})$, boric acid $(40 \mathrm{~g} / \mathrm{L})$ and sodium dodecyl sulfate $(0.1 \mathrm{~g} / \mathrm{L})$. The nickel patterns electroplated using nickel aminosulfonate plating bath has good flexibility, so the resistance stability after bending is high. Therefore, the FPC prepared by the template transfer process shows high resistance stability after bending, when the metal with high flexibility is electroplated. With specific additive in the plating bath, the plated copper patterns can also show better flexibility.
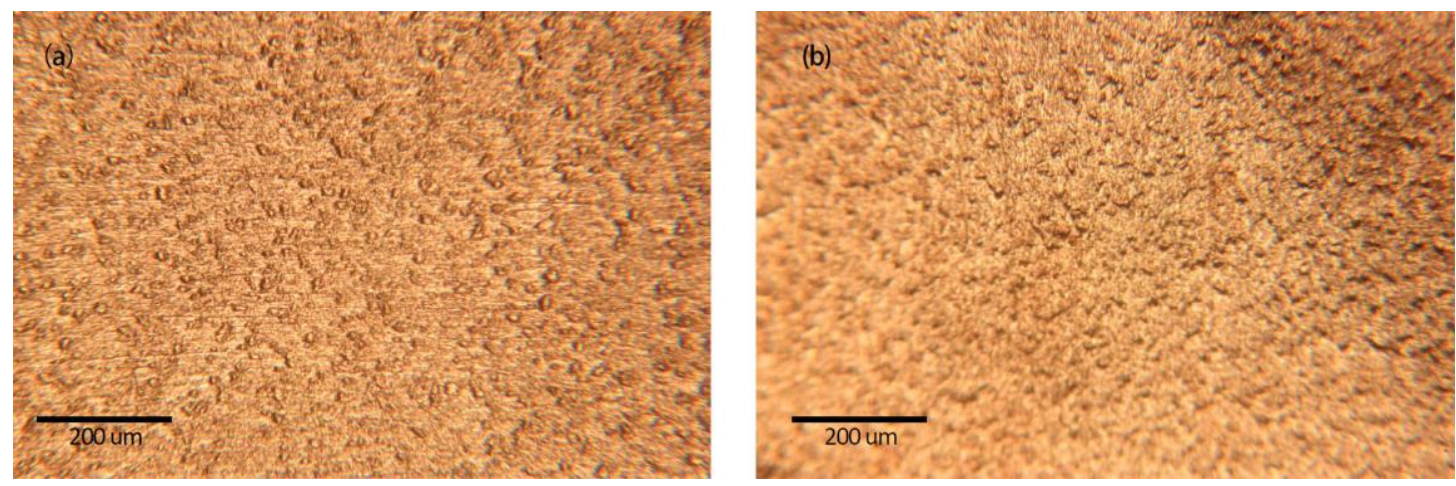

Figure S5. (a) Surface morphology of the carrier copper foil, (b) surface morphology of the plated copper film (the surface against carrier copper foil). The surface roughness of the carrier copper foil is $0.031 \mu \mathrm{m}$, while the surface roughness of the plated copper foil is $0.055 \mu \mathrm{m}$, which is the same level as that of the carrier copper 
foil. The plated copper surfaces can well fit the carrier copper surface from the concave parts to the raised parts, indicating that the template transfer process can multiple the micro structure of the template, therefore the process can be used in the micro patterning of a metal device.

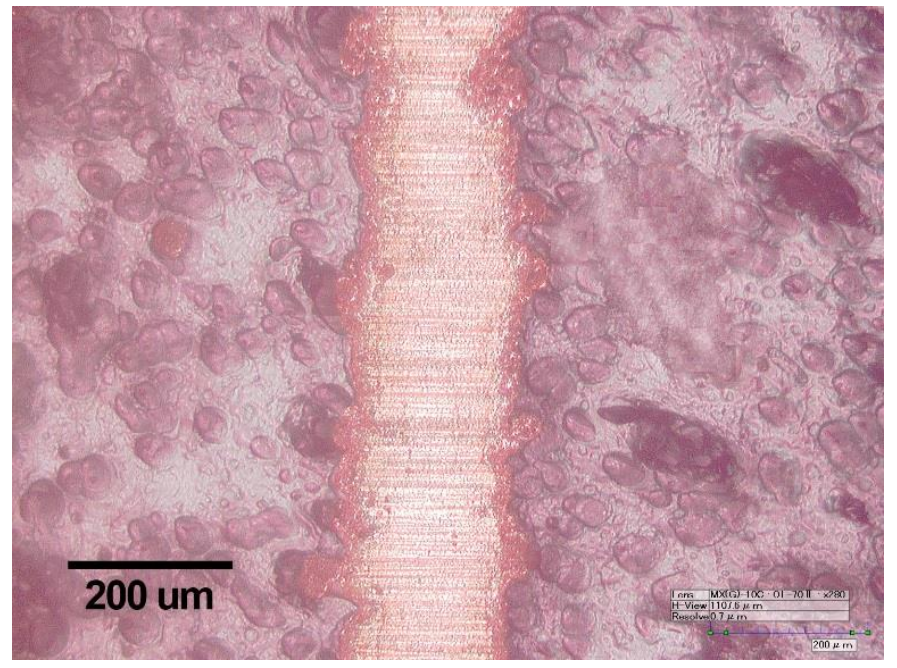

Figure S6. Copper line approximately $150 \mu \mathrm{m}$ in the width is prepared by the template transfer process. The limitation of the line width of the template transfer process is related to the resolution of the mask. With a better screen printer, $30-50 \mu \mathrm{m}$ copper line is possible to be prepared. 